\title{
Antibacterial Surfaces With Activity Against Antimicrobial Resistant Bacterial Pathogens and Endospores
}

\author{
Sandeep K. Sehmi, † Claudio Lourencot, Khaled Alkhuder, Sebastian D. Pike, Sacha Noimark, \\ Charlotte K. Williams, Milo S.P. Shaffer, Ivan P. Parkin*, Alexander J. MacRobert* and Elaine Allan* \\ S. K. Sehmi, C. Lourenco, Dr K. Alkhuder, Dr E. Allan, Division of Microbial Disease, UCL Eastman Dental \\ Institute, University College London, 256 Gray's Inn Road, London, WC1X 8LD, UK. E-mail: \\ e.allan@ucl.ac.uk
}

S. K. Sehmi, C. Lourenco, Prof I. P. Parkin, Materials Chemistry Research Centre, Department of Chemistry, University College London, 20 Gordon Street, London, WC1H OAJ, UK.

S. K. Sehmi, Prof A. J. MacRobert, UCL Division of Surgery and Interventional Science, University College London, Royal Free Campus, Rowland Hill Street, London, NW3 2PF, UK.

Dr S. Noimark, Department of Medical Physics and Biomedical Engineering, University College London, Gower Street, London, WC1E 6BT, UK.

Dr S. D. Pike, Prof C. K. Williams, Prof M. S. P. Shaffer, Department of Chemistry, Imperial College London, Imperial College Road, London, SW7 2AZ, UK.

tjoint first authors

*corresponding authors

\section{Keywords}

Crystal violet, zinc oxide nanoparticles, photo-active, antibacterial surface, antimicrobial resistance,

\begin{abstract}
Hospital-acquired bacterial infections are a significant burden on healthcare systems worldwide causing increased duration of hospital stays and prolonged patient suffering. We show that polyurethane containing crystal violet (CV) and 3-4 nm zinc oxide nanoparticles (ZnO NPs) possesses excellent bactericidal activity against hospital-acquired pathogens including multidrug resistant Escherichia coli, Pseudomonas aeruginosa, methicillin-resistant Staphylococcus aureus (MRSA) and even against highly-resistant endospores of Clostridioides (Clostridium) difficile. Importantly, we used clinical isolates of bacterial strains, a protocol to mimic the environmental conditions of a real exposure in the healthcare setting and low light intensity equivalent to that encountered in UK
\end{abstract}


hospitals ( $\sim 500$ lux). Our data shows that ZnO NPs enhance the photobactericidal activity of CV under low intensity light even with short exposure times and we show that this involves both Type I and Type II photochemical pathways. Interestingly, polyurethane containing ZnO NPs alone showed significant bactericidal activity in the dark against one strain of $E$. coli indicating that the NPs possess both lightactivated synergistic activity with CV and inherent bactericidal activity that is independent of light. These new antibacterial polymers are potentially useful in healthcare faciilties to reduce the transmission of pathogens between people and the environment.

\section{Introduction}

The antibacterial activity of zinc oxide nanoparticles (ZnO NPs) has attracted much attention in recent years due to the multi-functionality and biocompatibility of $\mathrm{ZnO}$ when synthesised with nanometre range diameters. ZnO NPs have shown selective toxicity towards bacteria and minimal effects on mammalian cells. ${ }^{[1]}$ They have many potential applications and are already used in the food-packaging industry as antibacterial agents against food-borne pathogens. ${ }^{[2]} \mathrm{ZnO}$ has a wide band gap $(3.3 \mathrm{eV})^{[3]}$ and is used as a UV protector in cosmetics as it possesses high optical absorption in the UV region. ${ }^{[4]}$ The mechanism of antibacterial action of ZnO NPs is unclear, although some studies suggest that their main activity comprises $\mathrm{Zn}^{2+}$-mediated disruption to the bacterial cell membrane. ${ }^{[5]}$ Another possible mechanism of action is the induction of reactive oxygen species (ROS), including hydrogen peroxide $\left(\mathrm{H}_{2} \mathrm{O}_{2}\right)$, which are harmful to bacterial cells. ${ }^{[6]}$ Several reports suggest that when activated by visible or UV light, $\mathrm{ZnO} N P s$ can generate ROS including $\mathrm{OH}^{-}, \mathrm{H}_{2} \mathrm{O}_{2}$, and ${ }^{1} \mathrm{O}_{2} \cdot{ }^{[2-5]}$

Hospital-acquired infections (HAls) are a major threat to patients, visitors and healthcare workers, causing an estimated 5000 deaths per year in the UK. ${ }^{[7]}$ In addition, they pose a significant economic burden on healthcare systems world-wide and are a particular risk for the elderly, children and patients with compromised immune systems.$^{[8]}$ As a result of the increasing incidence of HAls, which are often caused by multidrug resistant pathogens, the development of novel antibacterial strategies is urgent. ${ }^{[9]}$ Infections caused by methicillin-resistant Staphylococcus aureus (MRSA) and carbapenemresistant Enterobacteriaceae (CRE) infections are two of the major challenges currently faced by healthcare facilities as these bacteria are resistant to most currently available antibiotics. ${ }^{[10]}$ The overuse of antibiotic treatment itself presents problems in the healthcare environment, however, as it increases the risk of hospital-associated diarrhoea due to infection with Clostridioides (Clostridium) difficile. ${ }^{[11]}$ Patients with $C$. difficile infection shed endospores in their feces which are transmitted to other patients via frequently touched surfaces. These spores are able to persist in the environment for long time periods and if ingested by patients whose protective microbiota has been disrupted by 
broad spectrum antibiotics, they may germinate and produce toxins resulting in diarrhoeal disease. ${ }^{[11,12]}$

Antibacterial surfaces are effective in decreasing the incidence of HAls by reducing the spread of bacteria between patients, staff and frequently-touched surfaces such as call buttons, telephones, keyboards and bed rails. ${ }^{[13]}$ For surfaces to be effective at reducing bacterial transmission, they need to be self-sterilising and durable. One approach is to use non-toxic photosensitising agents which can be coated onto surfaces. ${ }^{[14-24]}$ Upon light activation, these photo-activated antimicrobial surfaces can generate cytotoxic ROS via a process known as photodynamic therapy (PDT). ${ }^{[14-24]}$ PDT can occur through two main pathways: (i) Type I (electron transfer) to produce superoxide anion radicals and/or (ii) Type II (energy transfer) to produce singlet oxygen $\left({ }^{1} \mathrm{O}_{2}\right) .{ }^{[25]}$ The superoxide radical anions can then undergo dismutation to generate hydrogen peroxide and then hydroxyl radicals via the Fenton process. PDT is an attractive strategy for treating bacterial infections since it has multiple targets in the bacterial cell thus reducing the likelihood of resistance developing. ${ }^{[26,27]}$

Typical photosensitisers such as methylene blue, toluidine blue $O$ and crystal violet (CV), can be incorporated into polymers and tested against bacteria following white light activation and in the dark. Previous studies carried out by our research group have shown the effectiveness of incorporated photosensitisers for medical devices and antibacterial surface coatings. ${ }^{[14-24]}$ Additionally, we have found that incorporating nanoparticles (e.g. $\mathrm{Au}, \mathrm{Cu}, \mathrm{TiO}_{2}, \mathrm{MgO}, \mathrm{ZnO}$ ) together with the photosensitiser can significantly enhance the bactericidal activity. ${ }^{[14-16,18-22]}$ We have also shown that the degree of synergy observed is dependent on the size of the nanoparticles and the light intensity used for activation. ${ }^{[6,14-16,18-21,26,27]}$ In previous studies, ${ }^{[14,32]}$ we found that small ZnO nanoparticles are particularly effective; here we synthesised highly soluble, small NPs stabilised by oleate ligands for investigation.for encapsulation into polyurethane. A limitation of previous work is that microbiological testing was performed on domesticated laboratory strains of bacteria which may no longer be representative. Here, we used we tested the materials using a broad range of clinicallyrelevant Gram-positive and Gram-negative bacterial pathogens including Pseudomonas aeruginosa, methicillin-resistant S. aureus (MRSA) and E. coli and importantly, we have included both recent clinical isolates expressing multidrug resistance and $C$. difficile endospores which are highly resistant to killing by other means including heat and chemical disinfection. ${ }^{[30,31]}$ In addition, we modified our previous protocol to more closely mimic the environmental conditions of a 'real world' exposure within a hospital environment.

\section{Results and Discussion}


In this work, we first synthesised small $\mathrm{ZnO}$ nanoparticles $(3-4 \mathrm{~nm})$ stabilised by oleate ligands, and subsequently encapsulated them within the polyurethane film. Previous reports have suggested a beneficial effect of using oleate groups in antimicrobial moieties. ${ }^{[32]}$ The oleate-capped ZnO NPs are themselves very soluble in organic solvents making them ideal candidates for the 'swellencapsulation-shrink' technique utilised here. The particles were prepared by the controlled hydrolysis of an organometallic precursor $\left(\mathrm{ZnEt}_{2}\right)$ in the presence of 0.2 equivalents of oleic acid (to give a 5:1 metal:ligand ratio). ${ }^{[33]}$ After preparation, the nanoparticles were kept in an inert environment (e.g. under $\mathrm{N}_{2}$ ) as evidence shows they may slowly ripen over several months if exposed to atmospheric moisture. ${ }^{[34]}$ The particles were characterised by powder X-ray diffraction and UVspectroscopy to determine the size of the particles, ${ }^{[35]}$ with freshly prepared samples consistently showing sizes between 3-4 nm. IR spectroscopy confirmed surface coordinated oleate ligands along with surface hydroxide groups ${ }^{[36]}$ (Fig S1). Elemental analysis showed final metal:ligand ratios of 5.35.4:1, suggesting a very slight loss of ligand during the nanoparticle synthesis. A Tauc plot measured the band onset of ZnO NPs suspended in toluene, estimating the band gap to be $\sim 3.48 \pm 0.01 \mathrm{eV}$ (Fig. S7, supporting information).

ZnO NPs were incorporated into $1 \mathrm{~cm}^{2}$ medical grade polyurethane samples using a simple and easily upscalable, 'swell-encapsulation-shrink' method (described in 1.1.3, supporting information). Once incorporated, ZnO-containing polymer squares were immersed in a $0.001 \mathrm{M}$ aqueous solution of $\mathrm{CV}$ in water, to produce a polymer containing both $\mathrm{CV}$ and $\mathrm{ZnO}(\mathrm{CVZnO})$. The modified polymers were characterised using UV-vis absorbance and X-ray photoelectron spectroscopy (XPS). In the UV-vis spectrum, polyurethane coated with either CV or CVZnO showed an absorbance maximum at $\lambda=590$ $\mathrm{nm}$ (Fig. S8), but no characteristic absorption peak for $\mathrm{ZnO}$ was observed presumably due to the low concentration of NPs encapsulated. XPS data confirmed that ZnO NPs were encapsulated and localised near the polymer surface (Fig. 1), showing a doublet in the $\mathrm{Zn} \mathrm{(2p)} \mathrm{region} \mathrm{indicating} \mathrm{the} \mathrm{presence} \mathrm{of}$ $\mathrm{Zn}$ in $\mathrm{ZnO}$. XPS depth profile data demonstrated an increase in zinc content within the polymer substrate with depth.

The photostability of CV- and CVZnO-coated polyurethane samples was examined under a 3880 lux white light source for up to 60 days (Fig. S9). The results from UV-vis spectroscopy indicated that both samples were relatively photostable, even under a light source 19 -fold more intense than that of many hospital wards and corridors ( 200 lux). ${ }^{[37,38]}$ Over the 60-day period, the CV-coated polymer showed a $34 \%$ reduction in peak maxima compared to $39 \%$ for the polymer containing CVZnO, suggesting that these materials are likely to exhibit reasonable long term photostability. Inductivelycoupled plasma-optical emission spectroscopy (ICP-OES) was used to determine if any zinc species leached from the $\mathrm{ZnO}$-incorporated polymer when the films were immersed in water. Modified 
polymer squares were immersed in distilled water for up to $48 \mathrm{~h}$. Results showed that small amounts of zinc species was leached from the polymer $(0.096 \pm 0.002 \mathrm{mg} / \mathrm{L}$ after $2 \mathrm{~h}$ and $1.008 \pm 0.006 \mathrm{mg} / \mathrm{L}$ after $48 \mathrm{~h})$.

(a)
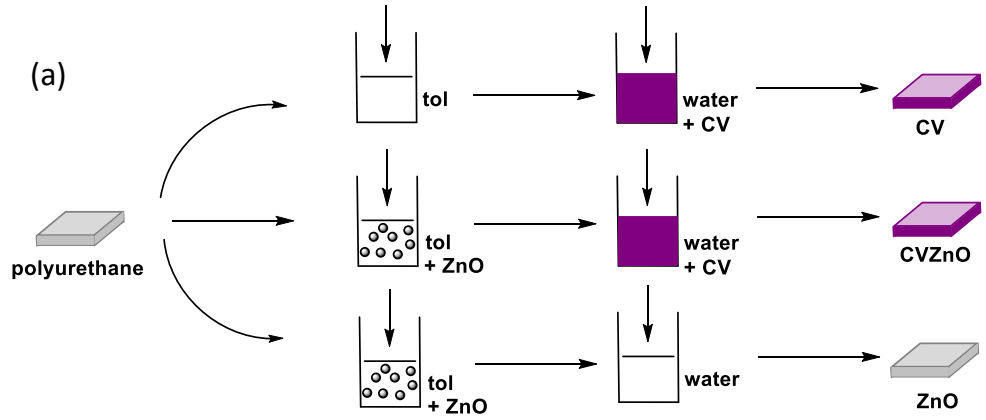

(b)

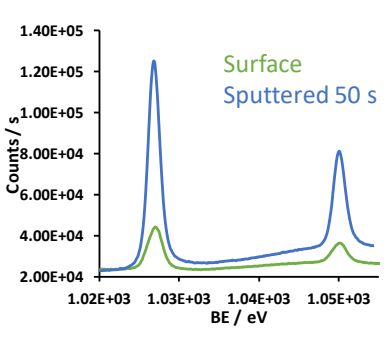

(c)

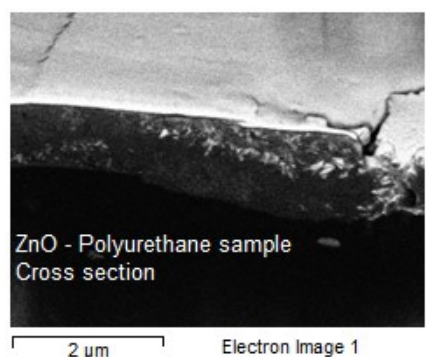

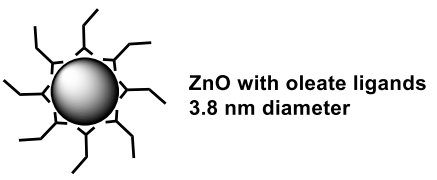

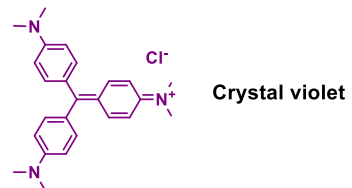

(d)

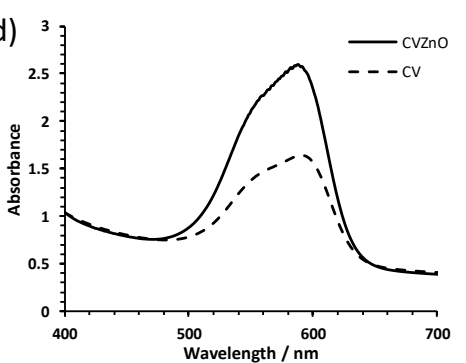

Fig. 1 (a). Schematic of the materials synthesis demonstrating that the control and test samples underwent the same preparation process, (b) overlaid XPS spectra for CVZnO in the $\mathrm{Zn}(2 \mathrm{p})$ region on the surface and after 50 s of sputtering. (c) SEM side-on image of the ZnO-polyurethane composite, (d) Uv-vis spectra of crystal violet impregnated polyurethane and crystal vilet-ZnO impregnated polyurethane.

The modified polymer samples were tested for antibacterial activity against different bacterial species in the dark and during exposure to ambient laboratory lighting ( 500 lux). Samples were exposed to E. coli ATCC 25922 for up to $3 \mathrm{~h}$ using the protocol described previously. ${ }^{[9]}$ The antibacterial activity of the samples was tested against this bacterium to enable a comparison with previous materials synthesised in our group. ${ }^{[14-22]}$ Within only $2 \mathrm{~h}$ of white light exposure (Fig. S10), CVZnO reduced the numbers of E. coli ATCC 25922 to below the detection limit and $\mathrm{ZnO}$ alone caused a $\sim 2$ log reduction in bacterial numbers $(P=0.001)$, whereas there was no significant reduction in bacterial viability on the control material. Even in the dark, after $2 \mathrm{~h}$ CVZnO demonstrated highly significant bactericidal activity against this strain of $E$. coli ( $\geq 4$ log reduction in bacterial numbers) and $\mathrm{ZnO}$ alone achieved $\sim 1.7$ log reduction $(P=0.001)$. This is the best activity achieved so far in our laboratory by a $\mathrm{ZnO}-$ containing polymer against a Gram-negative bacterium in the absence of a photosensitiser. ${ }^{[14,17,20,33]}$ 
The antibacterial efficacy of the polymers was then tested against other Gram-positive and Gramnegative bacteria (P. aeruginosa NTCC 10662, Staphylococcus aureus NCTC 13143 (this strain is a representative of epidemic clone EMRSA-16, one of two MRSA clones which predominate in the $\mathrm{UK}^{[30]}$ ), a recent clinical isolate of methicillin-resistant Staphylococcus aureus (MRSA 4742; obtained from P. Wilson, University College London Hospital), E. coli 1030, a strain expressing carbapenemase enzymes which renders the bacterium resistant to the drugs of last resort, the carbapenems; (obtained from J. Wade, King's College Hospital, London) and spores of $C$. difficile 630, a virulent and multidrug-resistant strain isolated from a hospital patient with severe pseudomembraneous colitis ${ }^{[39]}$. In previous experiments, we have placed the bacterial suspension on to the test polymer and used a coverslip to ensure good contact between the bacteria and the material. Here, in an effort to more closely mimic a natural exposure, the bacterial suspension was simply dropped on to the surface of the polymer and allowed to dry.

Fig. 2 summarises the antibacterial activity of the polymer samples against different hospital-acquired pathogens. The control material and polymer containing $\mathrm{ZnO}$ alone did not produce any significant bactericidal activity either in the dark or after white light illumination. Fig. 2(a) shows the bactericidal activity of the polymer samples against $P$. aeruginosa NCTC 10662 following $6 \mathrm{~h}$ of incubation in the light and dark. In the dark, CV alone reduced the numbers of $P$. aeruginosa by $\sim 0.6$ log whereas the combination of $\mathrm{CV}$ and $\mathrm{ZnO}$ in the dark was able to reduce the numbers by $\sim 1 \log$. With $6 \mathrm{~h}$ of white light activation, polyurethane containing $C V$ alone resulted in a $\sim 1.3$ log reduction in the numbers of $P$. aeruginosa whereas the polymer containing CVZnO reduced bacterial numbers to below the detection limit ( $\geq 4$ log reduction; $P=0.001$ ). Indeed, within only $4 \mathrm{~h}$ of light exposure, $C V Z n O$ reduced the number of $P$. aeruginosa by $\sim 2.5 \log$ (data not shown).

The samples were also tested against S. aureus NCTC 13143, a representative of the epidemic strain, EMRSA-16, one of two MRSA types which predominate in the UK (Fig. 2(b)). After $2 \mathrm{~h}$ in the dark, exposure to CVZnO resulted in a $\sim 2.4 \log$ reduction in the numbers of $S$. aureus and with $2 \mathrm{~h}$ of light exposure, the numbers of bacteria were reduced to below the detection limit ( $\geq 4 \log ; P=0.001$ ). The test samples also showed good activity against a recent clinical isolate of MRSA (strain 4742) producing a $3.4 \log$ reduction $(P=0.01)$ in the bacterial numbers after $2 \mathrm{~h}$ of exposure to white light $(\mathrm{Fig} . \mathrm{S} 10(\mathrm{c}))$.

The samples were then tested against E. coli 1030, a multidrug-resistant clinical isolate positive for both NDM and OXA-48-like carbapenemase enzymes. CVZnO demonstrated statistically significant bactericidal activity against $E$. coli 1030 in the dark within $4 \mathrm{~h}(\sim 1.9 \log$ reduction, $\mathrm{P}=0.001)$. 
Interestingly, in the light, $\mathrm{CV}$ alone reduced the numbers of $E$. coli 1030 by $\sim 1.5 \mathrm{log}$, whereas exposure to the CVZnO-containing polymer reduced the numbers by $\sim 4 \log (P=0.001)$.

Since a reduction in $C$. difficile spores within healthcare environments is currently a major challenge, we tested the photobactericidal efficacy of our samples against $C$. difficile endospores. No significant sporicidal activity was apparent in the dark. However, following $72 \mathrm{~h}$ of white light exposure, the polymer containing CVZnO achieved a further $\sim 1.2$ log reduction in the number of spores compared to the control. ( $P=0.001$; Fig. $2(d)$ It is not clear why a greater than 1 log reduction in the numbers of C. difficile spores apparently occurred on the control polymer. We assume that since no reduction in the spore counts was apparent on the control polymer in the dark, that this was due to reduced recovery of the spores from the surface of the light-exposed material as a result of drying. Whereas the bacterial suspension was still wet on the control polymer incubated in the dark at the end of the period of exposure, the suspension had dried on the surface of the control polymer incubated in the light.

The modified polymer samples containing both CVZnO demonstrated highly significant light-activated bactericial activity against all the healthcare-associated pathogens tested (Fig. 2) and even showed good activity against one strain of E. coli (ATCC 25922) in the dark (Fig. S10). Polyurethane containing only ZnO NPs also showed some bactericidal activity in the dark against this strain and light-activated synergy with CV (Fig. S10). For all the bacterial species tested, an increase in the antibacterial activity of $\mathrm{CV}$ was observed when ZnO NPs were combined implying that the nanoparticles are responsible for enhancing the intrinsic (dark) bactericidal activity of $\mathrm{CV}$ itself and and also enhancing the lightactivated bactericidal activity of the dye. The activity of the CVZnO polymer against $C$. difficile spores is encouraging since fecal shedding of spores by $C$. difficile-infected patients and contamination of environmental surfaces is the major infection source during hospital outbreaks; thus even a conservative reduction in spore numbers is likely to positively impact on infection control. 

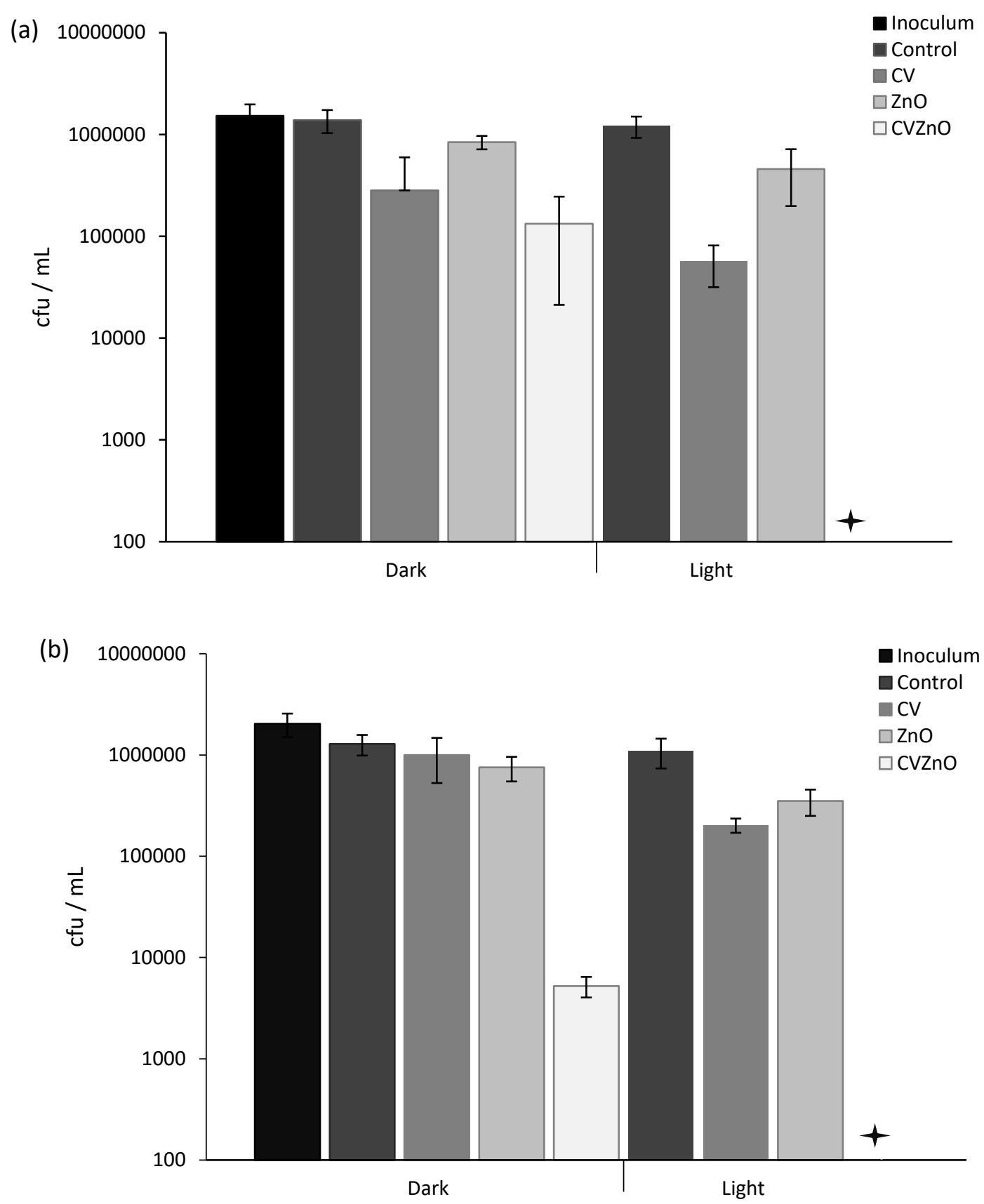


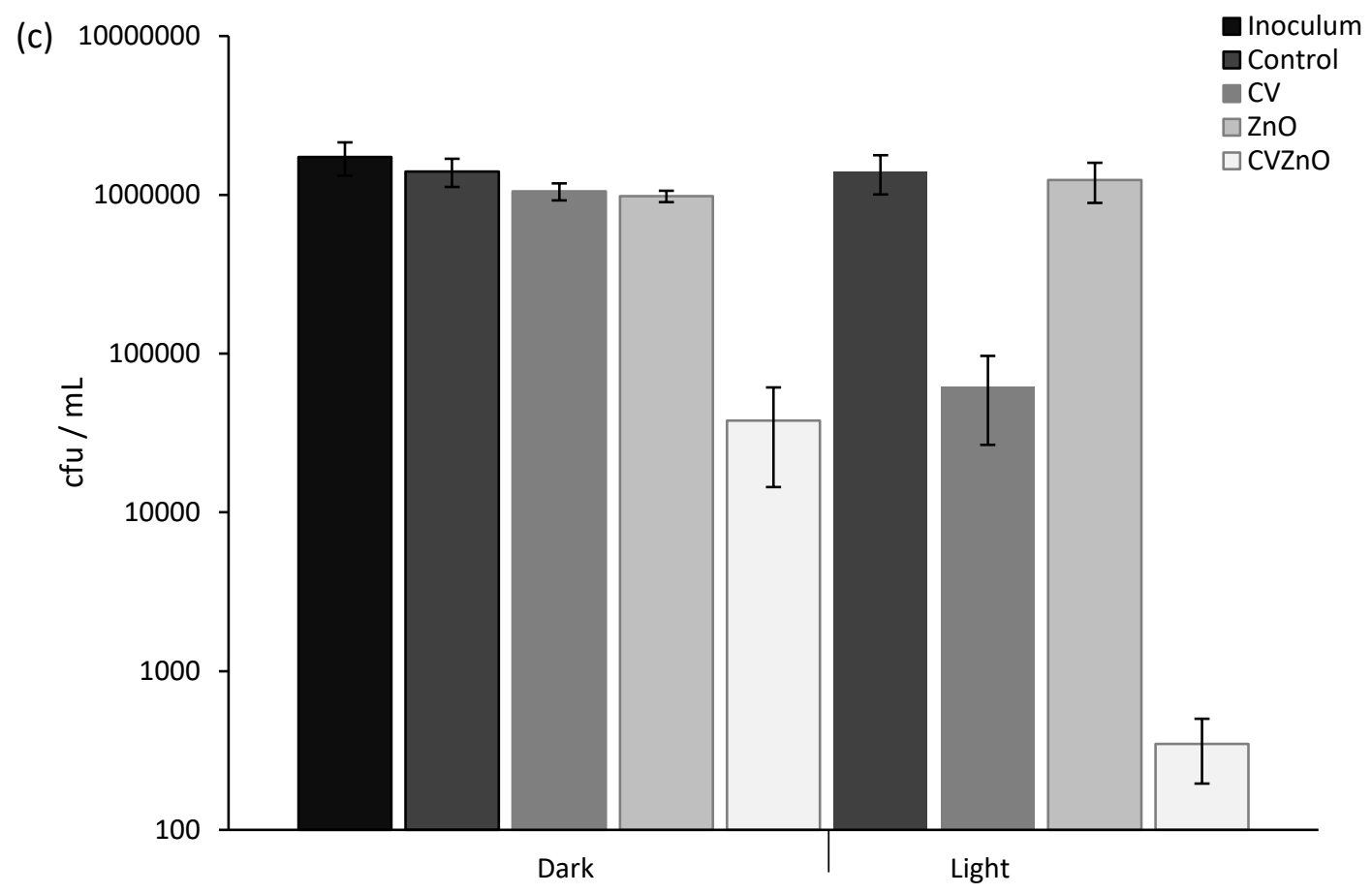

(d)

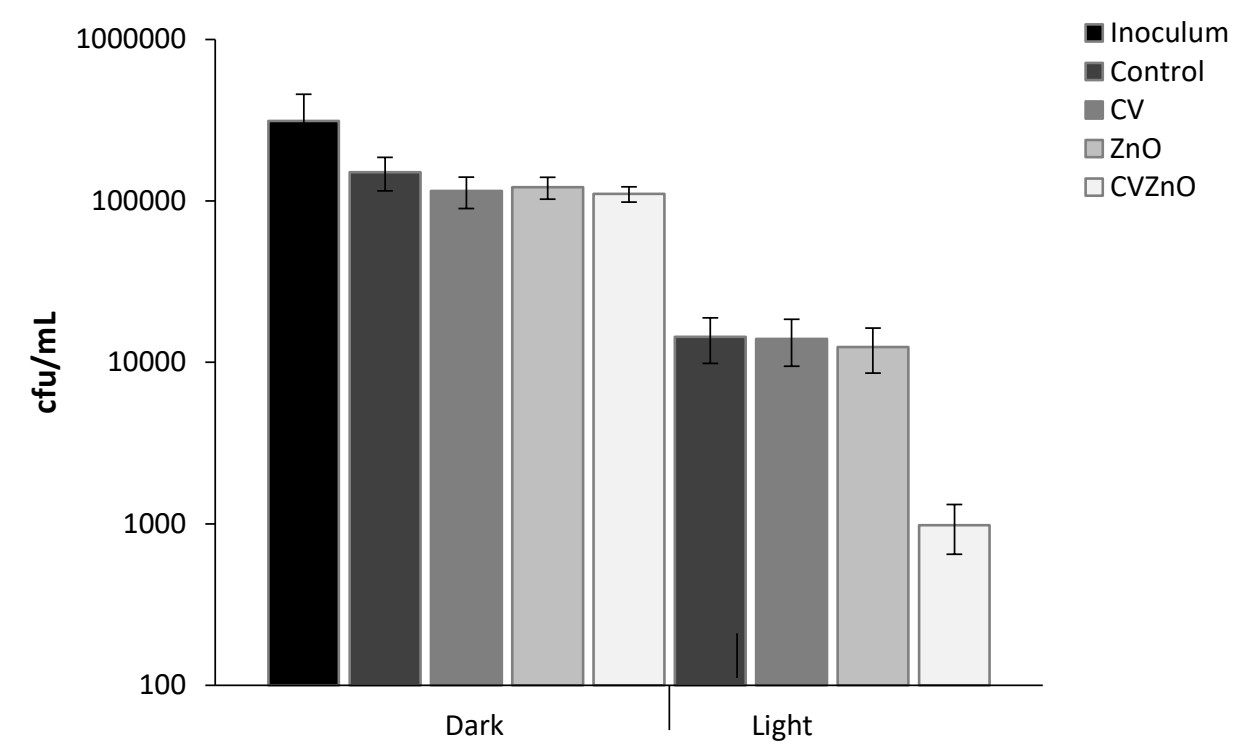

Fig. 2 Viable counts of bacteria after incubation at $20^{\circ} \mathrm{C}$ on modified polyurethane squares after exposure to standard laboratory white light (500 \pm 300 lux) and in the dark: (a) P. aeruginosa NTCC 10662 (6 h), (b) Staphylococcus aureus NCTC $13143(2 \mathrm{~h}),(\mathrm{c})$ E. coli $1030(4 \mathrm{~h})$ and (d) C. difficile 630 spores $(72 \mathrm{~h}) . \quad \mathrm{F}$ indicates that the viable count was below the detection limit of $100 \mathrm{cfu} / \mathrm{ml}$ 
Next we investigated the effect on the bactericidal activity of the polymers when different ligands and different metal:ligand ratios were used for the ZnO NP synthesis. ZnO NPs were synthesised with either oleate $\left(\mathrm{C}_{18} \mathrm{H}_{34} \mathrm{O}_{2}\right.$; with a double bond in the organic chain), stearate $\left(\mathrm{C}_{18} \mathrm{H}_{36} \mathrm{O}_{2}\right.$; no double bonds) or linoleate $\left(\mathrm{C}_{18} \mathrm{H}_{32} \mathrm{O}_{2}\right.$; two double bonds) carboxylate ligands. The structures of these ligands are shown in Fig. S11, supporting information). As shown in Table 1, ZnO capped with an oleate ligand was synthesised again but here a greater metal : ligand ratio was used - i.e. 10:1 compared to 5:1 used previously. Also, stearate and linoleate-capped $\mathrm{ZnO}(5: 1)$ were synthesised to see if changing the ligand chain would alter the bactericidal properties of the system, as the ligands, in the form of the free acids, are themselves known to possess antibacterial activity. ${ }^{[40-42]}$ The total ZnO surface area of $1 \mathrm{mg}$ of the NPs remained essentially consistent in all cases (Table 1), since particles with less ligand (more $\mathrm{ZnO} / \mathrm{g}$ ) are coincidentally larger in diameter with a lower surface area per particle. Therefore, the swelling solutions were all prepared with $1 \mathrm{mg}$ of $\mathrm{ZnO}$ per $\mathrm{mL}$. It is noteworthy that the solubility in organic solvents of these ZnO NPs was reduced compared to the original oleate-capped ZnO NPs $(5: 1)$ system. The antibacterial activity of polymer containing the different ligand:metal combinations was assessed using E. coli ATCC 25922 after $2 \mathrm{~h}$ of standard laboratory white light exposure ( 500 lux). The results showed that the bactericidal activity of linoleate- and stearate-capped ZnO was less than the oleate-capped $\mathrm{ZnO}$ in the light: the linoleate- and stearate-capped only achieved $\sim 1$ log reduction in the numbers of $E$. coli $(P=0.001)$ compared to $\geq 4 \log$ for the oleate-capped $\mathrm{ZnO}$ (Table 1). Linoleatecapped $\mathrm{ZnO}$ was the least soluble and did not demonstrate any significant kill in the dark. Stearatecapped $\mathrm{ZnO}$ reduced bacterial numbers by $\sim 1 \log$ in the dark $(P=0.001)$ whereas oleate-capped $\mathrm{ZnO}$ produced $\mathrm{a} \geq 4 \log$ reduction. Comparing the different ratios of oleate-capped $\mathrm{ZnO}$, the 10:1 ratio was not as effective as the 5:1 ratio presumably because the 10:1 oleate-capped ZnO NPs were bigger in size (Table 1). Within $2 \mathrm{~h}$ of white light exposure, the oleate-capped $\mathrm{ZnO}(10: 1)$ reduced the numbers of $E$. coli by $2 \log (P=0.001)$ and showed no kill in the dark. It appears that reducing the ligand coverage of the $\mathrm{ZnO}$ surface (the estimated surface coverage by ligand drops from $95 \%$ in the $5: 1$ ratio to $65 \%$ at 10:1) is not beneficial. As reported previously by ourselves and by others, this study confirms that the antibacterial activity of nanoparticles is size dependent. ${ }^{[6,14-22,28,29]}$

Table 1. Summary of the nanoparticle surface area and ligand coverage of all $\mathrm{ZnO}$ nanoparticles. Approximate diameter calculated from UV spectroscopy (Fig S6). Antibacterial activity of the ligands encapsulated into polyurethane (without CV against $E$. coli ATCC 25922 ) after $2 \mathrm{~h}$ exposure to white light ( $500 \pm 300$ lux).

\begin{tabular}{|c|c|c|c|c|c|c|}
\hline Ligand & Ratio & $\begin{array}{c}\text { wt \% ligand by } \\
\text { elemental analysis } \\
\text { (carbon \%) }\end{array}$ & $\begin{array}{c}\text { Approximate } \\
\text { Diameter } \\
(\mathrm{nm})\end{array}$ & $\begin{array}{c}\text { ZnO Surface } \\
\text { Area of } 1 \mathrm{mg}\end{array}$ & $\begin{array}{c}\text { Antibacterial } \\
\text { Estimated } \\
\text { Ligand }\end{array}$ & activity after $2 \mathrm{~h}$ \\
\hline
\end{tabular}




\begin{tabular}{|c|c|c|c|c|c|c|}
\hline & & & $\begin{array}{c}\text { of particles } \\
\left(\mathrm{m}^{2}\right)\end{array}$ & $\begin{array}{c}\text { Coverage (\% } \\
\text { ZnO surface) }\end{array}$ & $\begin{array}{c}\text { white light (500 } \\
\pm 300 \text { lux })\end{array}$ \\
\hline Oleate & $5: 1$ & 39 & 3.8 & 0.17 & 95 & $\geq 4$ log \\
\hline Oleate & $10: 1$ & 25.6 & 4.9 & 0.16 & 65 & 2 log \\
\hline Stearate & $5: 1$ & 40 & 3.6 & 0.18 & 93 & 1 log \\
\hline Linoleate & $5: 1$ & 35.2 & 4.0 & 0.17 & 86 & 1 log \\
\hline
\end{tabular}

In our previous study using $\mathrm{ZnO}$ nanoparticles which were larger than those studied herein, we showed that both Type I and II ROS generating pathways are involved in by studying the effects of ROS inhibitors on bactericidal activity. Likewise Bovis et al. showed that both Type I and Type II mechanisms can operate with silicone doped with methylene blue and nanogold. ${ }^{[43]}$

To investigate the mechanism responsible for the bactericidal activity of the CVZnO-containing polymers, either superoxide dismutase ${ }^{[44]}\left(\mathrm{SOD} ; 50 \mathrm{U} \mathrm{mL}^{-1}\right.$ ) was added to the system to remove superoxide anions or L-histidine $(1 \mathrm{mM})$ was included as a singlet oxygen quencher to determine the contribution made by a Type I or Type II photochemical pathway, respectively ${ }^{[14]}$. SOD or L-histidine was added to the bacterial suspension before exposure to the polymer and the antibacterial activity against E. coli ATCC 25922 and S. aureus NCTC 13143 was determined in the light and in the dark (data shown in Fig. S12-S13, supporting information). The results indicate that both Type I and Type II mechanistic pathways contribute to the antibacterial activity of CVZnO against both bacteria in the dark and in the light. The results also suggest that the Type I and Type II reactions occur at the same rate as both SOD and histidine reduced the bactericidal activity to a similar extent. Interestingly, the bactericidal activity of polyurethane containing ZnO alone against $E$. coli ATCC 25922 is barely affected by the presence of either inhibitor indicating that the mechanism does not involve the production of superoxide or singlet oxygen (Fig. S13) and may result from leached zinc ions, shown previously to make a minor contribution to antibacterial activity. ${ }^{[45,46]}$

To confirm the production of singlet oxygen in the CVZnO system under visible light activation, furfuryl alcohol (FFA) and L-ascorbic acid were used separately as singlet oxygen quenchers. Under visible light, the oxidative degradation of $\mathrm{FFA}^{[47]}$ showed that a significant amount of singlet oxygen was produced in the photoactivation of CVZnO (Table S2, supporting information) compared to CV alone, and none was produced from the polymer alone or from the polymer containing only $\mathrm{ZnO}$. The increase in singlet oxygen production is partly explained by UV-vis spectroscopy (Fig. S8) which shows that higher levels (by approximately a factor of two) of $\mathrm{CV}$ are incorporated when $\mathrm{ZnO}$ is present. In the dark, none of 
the modified samples caused any diminution of FFA (data not shown). It should be noted that FFA does not absorb in the visible spectrum and therefore was not deactivated during the experiment.

Using the same microbiological protocol and conditions, L-ascorbic acid (1 mM) was added to the bacterial suspension. CVZnO with L-ascorbic acid resulted in only a $\sim 2$ log reduction of $E$. coli ATCC 25922 under white light activation, compared to a reduction of $\geq 4 \log$ in the absence of the quencher (Fig. S14, supporting information). CV with L-ascorbic acid reduced the bacterial numbers by only $\sim 1$ log, compared to a 2 log reduction in the absence of quencher. No change in antibacterial activity was observed in the dark in the presence of quencher. These results suggest that upon white light illumination, chemical quenching of singlet oxygen occurs as it reacts readily with ascorbate, producing hydrogen peroxide. ${ }^{[48]}$ Furthermore, the combination of $\mathrm{ZnO}$ and $\mathrm{CV}$ produces more singlet oxygen than CV alone, whereas there is no evidence of singlet oxygen production by the polymer containing $\mathrm{ZnO}$ alone. It should be noted that L-ascorbic acid is not quenched without white light activation (i.e. dark kill).

We have shown mechanistic evidence for the photochemical pathways occurring within the CVZnO system when exposed to light and in the dark. We have also demonstrated that the combination of the smaller NPs and the oleic acid capping agent results in improved antibacterial activity, in comparison to previous work incorporating $\sim 15 \mathrm{~nm}$ ZnO NPs in polyurethane. ${ }^{[14]}$ For the first time, we prepared oleic acid-capped ZnO-incorporated polyurethane surfaces that achieve lethal photosensitisation of E. coli ATCC 25922 without a photosensitiser within 2 h (Fig. S10, supporting information). ICP-OES analysis indicated small amounts of zinc leaching from $\mathrm{ZnO}$-incorporated polyurethane within $2 \mathrm{~h}$. Whilst a similar amount of leaching is observed with previously studied dioctylphosphinate (DOPA)-capped ZnO NPs incorporated into polyurethane ${ }^{[32]}$ after $2 \mathrm{~h}$, we note that after $48 \mathrm{~h}$ approximately $4 \mathrm{x}$ more $\mathrm{Zn}$ is leached in the case of oleate-capped $\mathrm{ZnO}$. This suggests the ligand may play some role in the leaching mechanism. The antibacterial activity of $\mathrm{ZnO}$ alone could be attributed to leaching of $\mathrm{Zn}^{2+}$ from the polymer which is taken up by the bacteria. Mechanistic studies have shown that the NPs do not produce ROS species on their own but when combined with CV there is greater production of ROS and more significantly, singlet oxygen.

These antibacterial polymers show great promise as potential surfaces in hospitals to reduce the spread of HAls. Significant bactericidal activity was observed under low intensity lighting and in the dark, proving more effective than other antibacterial systems previously described which used much higher light intensties (above 10,000 lux). ${ }^{[17,19]}$ Additionally, these new bactericidal polymers have demonstrated efficacy against a much higher bacterial load than would occur in a hospital 
environment; $\sim 1 \times 10^{5} \mathrm{cfu} / \mathrm{cm}^{-2}$ of bacteria used in this investigation compared to an average of $1 \mathrm{x}$ $10^{2} \mathrm{cfu} / \mathrm{cm}^{-2}$ found in a clinical environment. ${ }^{[17,20,19]}$

\section{Conclusion}

Polyurethane containing crystal violet and 3-4 nm zinc oxide nanoparticles exhibited good bactericidal activity against clinical isolates of multidrug resistant hospital-acquired pathogens including Escherichia coli, Pseudomonas aeruginosa, methicillin-resistant Staphylococcus aureus (MRSA) and even showed activity against the highly-resistant endospores of Clostridioides (Clostridium) difficile. Importantly, activity was apparent with low light intensity equivalent to that encountered in UK hospitals suggesting that these surfaces could potentially contribute to reducing the cycle of transmission of healthcare-associated pathogens between people and the environment.

\section{Experimental Section}

Synthesis of oleate-capped ZnO nanoparticles: Oleic acid was placed into a Schlenk flask with a stirrer and dried under vacuum. Dry toluene was added to the ligand in a glovebox and then 5 equivalents of diethyl zinc $\left(\mathrm{ZnEt}_{2}\right)$ was added dropwise to the solution whilst stirring. A $0.4 \mathrm{M}$ solution of water in acetone was added to the mixture to hydrolyse the organometallic precursors to $\mathrm{ZnO}$. The final nanoparticle suspension was precipitated by adding acetone, centrifuged and washed by toluene/acetone and acetone with subsequent centrifugation steps. The particles were air dried overnight. To halt any ripening which may occur in the solid state the particles were stored under $\mathrm{N}_{2}$ gas or vacuum.

Preparation of polymer samples: Swelling solutions for incorporating oleate-capped $\mathrm{ZnO}$ nanoparticles into polyurethane were prepared by immersing polyurethane squares $\left(1 \mathrm{~cm}^{2}\right)$ into a toluene suspension containing $\mathrm{ZnO}(1 \mathrm{mg} / \mathrm{mL})$. The polymer samples were left to swell-encapsulate at room temperature for $24 \mathrm{~h}$ and then dipped into aqueous crystal violet solution in water $(0.001 \mathrm{M})$ for $72 \mathrm{~h}$ in the dark. Control samples (treated with toluene only), ZnO-encapsulated polyurethane and CVcoated polyurethane were also prepared for the microbiology experiments.

\section{Supporting Information}


Supporting information is available.

\section{Acknowledgements}

S.S. would like to thank Dr. S. Sathasivam from UCL for his help with XPS, Dr A. Goode at Imperial College London for SEM analysis and UCL for the award of an Impact studentship. S.P. would like to thank Sheng Hu from ICL for her help with ICP-OES.

\section{References}

[1] K. M. Reddy, K. Feris, J. Bell, D. G. Wingett, C. Hanley, A. Punnoose, Appl. Phys. Lett. 2007, 90, 1.

[2] A. A. Tayel, W. F. El-Tras, S. Moussa, A. F. El-Baz, H. Mahrous, M. F. Salem, L. Brimer, J. Food. Saf. 2011, 31, 211.

[3] Q. Fan, J. Yang, Y. Yu, J. Zhang, J. Cao, Chem. Eng. Trans. 2015, 46, 985.

[4] M. Sudha, M. Rajarajan, J. Appl. Chem. 2013, 3, 45-53.

[5] Y. Xie, Y. He, P. L. Irwin, T. Jin, X. Shi, Appl. Environ. Microbiol. 2011, 77, 2325.

[6] K. R. Raghupathi, R. T. Koodali, A. C. Manna, Langmuir, 2011, 27, 4020.

[7] E. R. M Sydnor, T. M. Perl, Clin. Microbiol. Rev. 2011, 24, 141.

[8] Centers for Disease Control and Prevention: Review of Scientific Data Regarding Transmission of Infectious Agents in Healthcare Settings, 2007.

[9] N. Matsunaga, K. Hayakawa, Lancet Global Health 2018, 6, E934.

[10] T. T. Yoshikawa, Clin. Infect. Dis. 2000, 31, 1414.

[11] M. Hickson, Ther. Adv. Gastroenterol. 2011, 4, 185.

[12] S. Khanna, D. S. Pardi, Mayo. Clin. Proc. 2012, 87, 1106.

[13] World Health Organization Guidelines on Hand Hygiene in Health Care: a Summary, 2009.

[14] S. Sehmi, S. Noimark, J. C. Bear, W. J. Peveler, M. Bovis, E. Allan, A. J. MacRobert, I. P. Parkin, J. Mater. Chem. B. 2015, 3, 6490. 
[15] S. Noimark, C. W. Dunnill, C. W. M. Kay, S. Perni, P. Prokopovich, S. Ismail, M. Wilson, I. P. Parkin, J. Mater. Chem. 2012, 22, 15388.

[16] S. Perni, C. Piccirillo, A. Kafizas, M. Uppal, J. Pratten, M. Wilson, I. P. Parkin, J. Clust. Sci. 2010, $21,427$.

[17] E. Ozkan, E. Allan, I. P. Parkin, RSC Adv. 2014, 4, 51711.

[18] G. B. Hwang, E. Allan, I. P. Parkin, ACS Appl. Mater. Inter. 2015, 8, 15033.

[19] E. Ozkan, T. F. Ozkan, E. Allan, I. P. Parkin, RSC Adv. 2015, 5, 8806.

[20] S. Noimark, J. Weiner, N. Noor, E. Allan, C. K. Williams, M. S. P. Shaffer, I. P. Parkin, Adv. Funct. Mater. 2015, 25, 1367.

[21] S. Noimark, K. Page, J. C. Bear, C. Sotelo-Vazquez, R. Quesada-Cabrera, Y. Lu, E. Allan, J. A. Darr, I. P. Parkin, Faraday Discuss. 2014, 175, 273.

[22] T. J. Macdonald, K. Wu, S. K. Sehmi, S. Noimark, W. J. Peveler, H. du Toit, N. H. Voelcker, E. Allan, A. J. MacRobert, A. Gavriilidis, I. P. Parkin, Sci. Rep. 2016, 6, 39272.

[23] M. A. Biel, C. Sievert, M. Usacheva, M. Teichert, E. Wedell, N. Loebel, A. Rose, R. Zimmermann. Lasers Surg. Med. 2011, 43, 586.

[24] N. M. M. Moura, M. Esteves, C. Vieira, G. M. S. R. O. Rocha, M. A. F. Faustino, A. Almeida, J. A. S. Cavaleiro, C. Lodeiro, M. G. P. M. S. Neves. Dyes and Pigments 2019, 160, 361.

[25] P. Mroz, A. Yaroslavsky, G. B. Kharkwal, M. R. Hamblin, Cancers, 2011, 3, 2516.

[26] A. Chaiviello, I. Postiglione, G. Palumbo, Cancers, 2011, 3, 1014.

[27] R. R. Allison, K. Moghissi, Clin. Endosc. 2013, 46, 24.

[28] S. Pal, Y. K. Tak, J. M. Song, Appl. Environ. Microbiol. 2007, 73, 1712.

[29] Y. Jeong, D. W. Lim, J. Choi, Adv. Mater. Sci. Eng. 2014, 2014, 1.

[30] S. Das, C. J. Anderson, A. Grayes, K. Mendoza, M. Harazin, D. M Schora, L. R. Peterson, Antimicrob. Agents. Ch. 2013, 57, 4551.

[31] M. M. Nerandiz, J. L. Cadnum, M. J. Pultz, C. J. Donskey. BMC. Infect. Dis. 2010, 10, 1.

[32] S. K. Sehmi, S. Noimark, S. D. Pike, J. C. Bear, W. J. Peveler, C. K. Williams, M. S. P. Shaffer, E. Allan, I. P. Parkin, A. J. MacRobert. ACS Omega 2016, 1, 334. 
[33] K. L. Orchard, M. S. P. Shaffer, C. K. Williams, Chem. Mater. 2012, 24, 2443.

[34] M. Ali, M. Winterer, Chem. Mater. 2010, 22, 85.

[35] E. A. Meulenkamp, J. Phys. Chem. B. 1998, 102, 5566.

[36] I. P. Silverwood, C. W. Keyworth, N. J. Brown, M. S. P. Shaffer, C. K. Williams, K. Hellgardt, G. H. Kelsall, S. G. Kazarian. Appl. Spectrosc. 2014, 68, 88.

[37] S. K. Sehmi, S. Noimark, J. Weiner, E. Allan, A. J. MacRobert, I. P. Parkin, Appl. Mater. Inter. 2015, 7, 22807.

[38] S. K. Sehmi. PhD Thesis, University of London, 2016

[39] M. Sebaihia, B. W. Wren, P. Mullany, N. F. Fairweather, N. Minton, R. Stabler, N. R. Thomson, A. P. Roberts, A. M. Cerdeno-Tarraga, H. Wang H, M. T. G. Holden, A. Wright, C. Churcher, M. A. Quail, S. Baker, N. Bason, K. Brooks, T. Chillingworth, A. Cronin, P. Davis, L. Dowd, A. Fraser, T. Feltwell, Z. Hance, S. Holroyd, K. Jagels, S. Moule, K. Mungall, C. Price, R. Rabbinowitsch, S. Sharp, M. Simmonds, K. Steven, L. Unwin, S. Whithead, B. Dupuy, G. Dougan, B. Barrell, J. Parkhill, Nat. Genet. 2006, 38, 779.

[40] C. J. Zheng, J. Yoo, T. Lee, H. Cho, Y. Kim, W. Kim, FEBS Lett. 2005, 579, 5157.

[41] M. Chandrasekaran, K. Kannathasan, V. Venkatesalu, Z. Naturforsch. C. 2008, 63, 331.

[42] J. Choi, N. Park, S. Hwang, J. H. Sohn, I. Kwak, K. K. Cho, I. S. Choi, J. Environ. Biol. 2013, 34, 673.

[43] M. J. Bovis, S. Noimark, J. H. Woodhams, C. W. M. Kay, J. Weiner, W. J. Peveler, A. Correia, M. Wilson, E. Allan, I. P. Parkin, A. J. MacRobert, RSC Adv, 2015, 5, 54830.

[44] K. Ergaieg, M. Chevanne, J. Cillard, R. Seux, Solar Energy, 2008, 82, 1107.

[45] S. K. Sehmi, S. Noimark, S. D. Pike, J. C. Bear, W. J. Peveler, C. K. Williams, M. S. P. Shaffer, E. Allan, I. P. Parkin, A. J. MacRobert, ACS Omega, 2016, 1, 334.

[46] Y. Li, W. Zhang, J. Niu, Y. Chen, ACS Nano, 2012, 6, 5164.

[47] W. R. Haag, J. Hoigne, E. Gassman, A. M. Braun, Chemosphere. 1984, 13, 631.

[48] G. G. Kramarenko, S. G. Hummel, S. M. Martin, G. R. Buettner, Photochem. Photobiol. 2006, 82, 1634. 